\title{
PENGEMBANGAN MEDIA PEMBELAJARAN BERBASIS POP UP BOOK AUDIOVISUAL TENTANG TATA CARA BERWUDHU UNTUK ANAK TK KELOMPOK B
}

\author{
Rizka Putri Cahyani ${ }^{1}$, Ahmad Samawi ${ }^{2}$, Rosyidamayani Twinsari Maningtya ${ }^{3}$ \\ 1, 2,3 Universitas Negeri Malang
}

\begin{abstract}
The development of religious and moral values is very important to instill from an early age in children because it is related to the formation of morals which is an asset in the child's life. In Permendikbud no. 137 of 2014 article 10 states that the level of developmental achievement of children aged 5-6 years. One of them is about doing worship. In learning the procedures for ablution. The results of the development needs analysis show that the variety of media to get used to the procedures for ablution for AUD is still limited. Observations of researchers from several schools, the media used by the teacher were pictures and miniatures. Researchers see the need for the development of learning media based on audiovisual pop-up books on the procedures for ablution. Pop up books are assessed from 3 aspects, namely efficiency, attractiveness, and effectiveness. The pop up book is modified with audio features that aim to make it easier for children to understand the ablution movements, intentions and prayers after ablution. The research method used is the ADDIE development model. The results of the evaluation of the material expert and media expert validation show a percentage of $88 \%$ which means very valid, the results of the assessment from the user expert is $92 \%$ which means very interesting, the results of the assessment of children's learning achievement are $97 \%$ which means very effective. The results of all the validation assessment of the audiovisual pop up book learning media on the procedures for ablution in Kindergarten Group B children showed a percentage of $92 \%$, meaning that this media was very suitable for use.
\end{abstract}

Keyword: Audiovisual pop up book, Wudu Procedures, Kindergarten Children Group B

\begin{abstract}
Abstrak: Pengembangan nilai agama dan moral sangat penting ditanamkan sejak dini kepada anak karena berkenaan dengan pembentukan akhlak yang merupakan modal dalam kehidupan anak kelak. Dalam Permendikbud no. 137 tahun 2014 pasal 10 menyatakan bahwa, tingkat pencapaian perkembangan anak usia 5-6 tahun. Salah satunya tentang mengerjakan ibadah. Dalam pembiasaan pembelajaran tata cara berwudhu. Hasil analisis kebutuhan pengembangan,variasi media untuk membiasakan tata cara berwudhu bagi AUD masih terbatas. Pengamatan peneliti dari beberapa sekolah, media yang digunakan guru yaitu gambar, dan miniatur. Peneliti memandang perlu adanya pengembangan media pembelajaran berbasis pop up book audiovisual tentang tata cara berwudhu. Pop up book dinilai dari 3 aspek yakni keefesiensi, kemenarikan, dan keefektifan. Pop up book di modifikasi dengan fitur audio bertujuan memudahkan anak memahami gerakan berwudhu, niat dan doa setelah berwudhu. Metode penelitian yang digunakan yaitu model pengembangan ADDIE. Hasil penilaian validasi ahli materi dan ahli media menunjukkan presentase $88 \%$ yang berarti sangat valid, hasil penilaian dari ahli pengguna sebesar $92 \%$ yang berarti sangat menarik, hasil dari penilaian capaian belajar anak sebesar $97 \%$ yang berarti sangat efektif. Hasil seluruh penilaian validasi media pembelajaran pop up book audiovisual tentang tata cara berwudhu pada anak TK Kelompok B menunjukkan presentase $92 \%$ mengartikan media ini sangat layak digunakan.
\end{abstract}

Kata Kunci: Pop up book Audiovisual, Tata Cara Berwudhu, Anak TK Kelompok B

\footnotetext{
'Universitas Negeri Malang, Email: rizkaputricahyani|⿴囗玉 gmail.com

${ }^{2}$ Universitas Negeri Malang, Email: ahmadsamawi国gmail.com

${ }^{3}$ Universitas Negeri Malang, Email: rasyidamayanitwinsarimaningtya回gmail.com
} 


\section{PENDAHULUAN}

Penggunaan media pembelajaran yang baik diyakini mampu menunjang enam aspek perkembangan anak. Bidang pengembangan moral dan nilai-nilai agama sangat penting ditanamkan sejak dini kepada anak karena berkenan dengan pembentukan akhlak yang merupakan modal dalam kehidupan anak kelak. Perkembangan Nilai, Agama, dan Moral di PAUD memiliki tingkat pencapaian tersendiri sesuai dengan yang tertera didalam Permendikbud No.137 Tahun 2014. Diantara enam aspek tersebut salah satunya perkembangan Nilai Agama dan Moral. Dalam Permendikbud tersebut menyatakan bahwa, tingkat pencapaian perkembangan anak usia 5-6 tahun yang meliputi: Mengenal agama yang dianut; Mengerjakan ibadah; Berperilaku jujur, penolong, sopan, hormat, sportif, dsb; Menjaga kebersihan diri dan lingkungan; Mengetahui hari besar agama; Menghormati (toleransi) agama orang lain. Salah satu yang dapat diterapkan dalam pengembangan aspek nilai agama dan moral, yaitu mengerjakan ibadah. Salah satu jenis ibadah dalam agama islam yang dapat diajarkkan pada AUD adalah berwudhu.

Dari hasil studi analisis kebutuhan pengembangan, diketahui bahwa variasi media untuk membelajarkan tata cara berwudhu bagi AUD masih sangat terbatas. Pengamatan peneliti dari beberapa sekolah, media yang digunakan guru hanya berupa gambar, dan miniature. Media-media tersebut hanya dapat mensosialisasikan berwudhu tanpa bisa mengetahui detailnya, sehingga media ini praktis, hanya efektif digunakan oleh anak, bila didampingi oleh guru maupun orangtua. Dalam penelitian dan pengembangan ini, peneliti bermaksud memberikan inovasi dari pop up book yang sebelumnya. Inovasi yang peneliti lakukan adalah penambahan fitur audiovisual mengeluarkan suara atau bunyi, media pembelajaran pop up book audiovisual ini tidak hanya sekedar menarik dan praktis, namun juga efektif dan efesien. Tujuan penelitian dan pengembangan ini adalah (1) Produk pop up book audiovisual menghasilkan produk media pembelajaran yang menarik, efektif, dan juga efesien saat digunakan. (2) Produk pop up book audiovisual ini jugadilengkapi dengan fitur audio bertujuan untuk memudahkan anak dalam memahami pembiasaan tata cara berwudhu, niat berwudhu, dan juga doa setelah berwudhu.

Salah satu sarana yang digunakan untuk membentuk tumbuh kembang generasi penerus adalah pendidikan. Melalui pendidikan di usia dini juga karakter anak dapat terbentuk. Menurut Suyadi \& Ulfah (2015) Pendidikan Anak Usia Dini pada hakikiatnya ialah pendidikan yang diselenggarakan dengan tujuan untuk memfasilitasi pertumbuhan dan perkembangan anak secara menyeluruh atau menekankan pada pengembangan seluruh aspek kepribadian anak. Oleh karena itu, PAUD memberikan kesempatan kepada anak untuk mengembangkan keperibadian dan potensi secara maksimal, melalui berbagai aspek perkembangan, seperti : nilai agama dan moral, kognitif, sosial emosional, fisik motorik, dan seni. Menurut UU No. 20 Tahun 2003 mengenai sistem pendidikan nasional menyatakan bahwa Pendidikan anak usia dini adalah upaya pembinaan yang ditujukan kepada anak sejak lahir sampai dengan usia enam tahun yang dilakukan melalui pemberian rangsangan pendidikan untuk membantu pertumbuhan dan perkembangan jasmani dan rohani agar anak memiliki kesiapan dalam memasuki pendidikan lebih lanjut. Menurut UU No. 20 Tahun 2003 Pendidikan dapat dijadikan upaya mengatasi permasalahan moral. Selain itu, ada beberapa karakteristik anak kelompok B menurut), yaitu memahami aturan yang 
berlaku ditempat yang berbeda-beda, mengembangkan kontrol terhadap perasaan mereka, mau berbagi dan mengantri, dapat menerima penjelasan, dan memahami rasa keadilan. juga menjabarkan perkembangan motorik halus pada anak usia dini yaitu:

a. dapat membangun menara tinggi dan kokoh dengan menggunakan balok,

b. dapat menangkap bola menggunakan satu tangan walaupun dilempar dengan jarak 1 meter,

c. dapat berpakaian secara tepat,

d. dapat menyesuaikan gambar dengan tempatnya,

e. dapat menunjukan tangan mana yang lebih serig digunakan, kanan atau kiri.

Pendidik atau orang tua perlu memperhatikn perkembangan anak usia dini yang berada pada masa prasekolah, masa meniru, masa bermain dan anak memiliki keragaman Perkembangan anak pada usia 5-6 tahun harus mendapatkan layanan yang baik dari pendidik atau orangtua, agar anak dapat melewati tahaptahap perkembangan sesuai dengan tahapan usianya. Menurut Asyhar (2012), Media audiovisual terbagi menjadi dua macam, yakni: (1) audiovisual murni yaitu baik unsur suara maupun unsur gambar berasal dari satu sumber seperti video kaset; dan (2) audiovisual tidak murni yaitu unsur suara dan unsur gambarnya berasal dari sumber yang berbeda, misalnya film bingkai suara yang unsur gambarnya berasal dari slides proyektor dan unsur suaranya berasal dari tape recorder. Pada produk penelitian dan pengembangan Ini audiovisual yang digunakan yaitu audiovisual yang tidak murni, yaitu media yang berupa buku yang nantinya akan ada suara yang berasal dari music box. Media pop up adalah salah satu media berbentuk 3 dimensi, timbul dan dapat bergerak saat dibuka. Pop up terbuat dari kertas. Tampilan pop up tentunya tidak sama dengan tampilan buku biasa. Tampilan pop up lebih menarik karena memiliki bentuk 3 dimensi dan memilki varian warna yang menarik. Azzam (2018), mengatakan bahwa berwudhu secara bahasa (etimologi) diambil dalil lafat $a l$ wadha'ah yang artinya bagus dan bersiih. Sedangkan menurut terminologi syara', wudhu berarti aktivitas bersuci dengan media air yang berhubungan dengan empat anggota tubuh, muka, kedua tangan, kepala, daan kedua kaki. Berdasarkan dalil dari Al-qur'an dalam surat Al-maidah (5) ayat 6, dan hadist yang diriwayatkan oleh Abu Hurairah, bukhori-muslim. Azzam (2018), mengatakan bahwa wudhu merupakan keistimewaan yang diberikan kepada umat islam yang kelak dihari kiamat akan membekaskan binar cahaya diwajah, tangan dan kaki, merujuk pada hadist Abu Hurairah.

\section{METODOLOGI PENELITIAN}

Penelitian ini bertujuan untuk mengembangkan media pembelajaran berupa pop-up book audiovisual pada aspek nilai, agama, dan moral terkhususnya pada tata cara berwudhu untuk anak TK kelompok B. Pada saat ini, peneliti menggunakan model ADDIE ini dikarenakan tahapan-tahapan pada model ini sederhana, dan sesuai dengan yang digunakan untuk mengembangkan terkhusus dalam mengembangkan media pop up book ini. Model pengembangan ADDIE yang terdiri dari lima tahapan yang meliputi: a) Tahap Analisis (Analysis) b) Perencanaan (Design) c) Pengembangan (Developmen) d) Penerapan (Implementasi) e) Evaluasi (Evaluation).

Pelaksanaan validasi ahli materi dan ahli media dilakukan secara online. Penelitian dilakukan pada Agustus 2020. Teknik pengumpulan data dalam penelitian ini adalah wawancara, observasi, angket. Angket kelayakan media pembelajaran untuk ahli materi. Instrumen penelitian ini menggunakan instrumen ini digunakan untuk mengetahui seberapa dalam materi yang disampaikan melalui media pembelajaran 
pop up book audiovisual. Lembar validasi ahli media digunakan untuk mengetahui kelayakan media tersebut dalam pembelajaran. Lembar validasi ahli pengguna untuk mengetahui kemudahan dalam penggunaan media pop up book audiovisual, lembar capaian belajar anak untuk mengetahui pengaruh media pop up book audiovisual dalam menyampaikan informasi tentang tata cara berwudhu. Angket kelayakan media pembelajaran untuk ahli media, angket kelayakan media pembelajaran untuk pengguna, angket capaian belajar anak.

\section{HASIL PENELITIAN DAN PEMBAHASAN}

Berdasarkan penjelasan diatas, maka peneliti membuat istrumen penelitian yang telah dimodifikasi dan disesuaikan dengan kebutuhan penelitian. Peneliti membagi instrumen menjadi lima, yaitu: 1) Lembar validasi oleh ahli media yang terdiri dari spek tampilan dan pemrogaman, 2) Lembar validasi oleh ahli media yang terdiri dari aspek materi, 3) Lembar validasi ahli pengguna, 4) Lembar capaian belajar anak.Menurut Sugiono (2015) Teknik pengumpulan data merupakan langkah yang paling stratedi dalam penelitian, tujuan utama yang diperoleh dari penelitian ialah mendapatkan data dengan menggunakan mix metode. Tanpa mengetahui teknik pengumpulan data, maka peneliti tidak akan mendapatkan data untuk memenuhi standar data yang ditetapkan. Adapun rumus yang digunakan untuk mengetahui kelayakan media adalah sebagai berikut:

$$
\mathrm{V}-a h=\frac{T S e}{T S h} \times 100 \%
$$

Sumber: (Akbar, 2013)

Keterangan:

Vah = Validasi ahli media

$T S e=$ Total Skor empirik yang dicapai

$T S h=$ Total Skor yang diharapkan $100 \%=$ Konstanta
Hasil perhitungan dapat disimpulkan berdasarkan tabel kriteria penelitian tingkat keefektifan, kevalidan, dan praktis dari media. Penilaian media pembelajaran popup book audiovisual tata cara berwudhu dalam penelitian dan pengembangan ini ditentukan dengan nilai minimal cukup valid. Penjelasan mengenai kriteria dalam menentukan validasi produk yang akan disajikan dalam tabel berikut:

Tabel 3.8 Kriteria Penilaian Tingkat Kevalidasian Produk

\begin{tabular}{ccc}
\hline No & $\begin{array}{c}\text { Kriteria } \\
\text { Validitas }\end{array}$ & $\begin{array}{c}\text { Tingkat } \\
\text { Validitas }\end{array}$ \\
\hline 1 & $81,00 \%-$ & Sangat valid \\
& $100,00 \%$ & \\
\hline 2 & $61,00 \%-$ & Cukup valid \\
& $80,00 \%$ & \\
\hline 3 & $41,01 \%-$ & Kurang valid \\
& $60,00 \%$ & \\
\hline 4 & $21,00 \%-$ & Tidak valid \\
& $40,00 \%$ & \\
\hline 5 & $00,00 \%-$ & Sangat tidak \\
& $20,00 \%$ & valid \\
\hline \multirow{3}{*}{ Data yang diperoleh dari ahli }
\end{tabular}
materi yaitu data kuantitatif dan kualitatif. Data kuantitatif diperoleh dari penilaian pernyataan sebanyak 10 butir dengan rentang nilai 1-5 dengan rincian angka 5 nilai tertinggi, sedangkan data kualitatif diperoleh dari saran dan kritik secara keseluruhan. Pemaparan data validasi ahli materi disajikan dalam tabel berikut.

Berdasarkan instrument validasi ahli terdapat 10 item validasi. Jumlah skor dapat dilihat dari ahli materi adalah 46 Untuk menentukan nilai(\%) hasil kriteria vaidasi dapat dihitung menggunakan rumus berikut ini:

$$
\begin{aligned}
\text { Vah } & =\frac{\text { Tse }}{\mathrm{T} s h} \times 100 \%=\ldots \% \\
& =\frac{42}{50} \times 100 \%=\mathbf{8 4 \%}
\end{aligned}
$$


Mengacu pada tabel kriteria validasi, maka hasil penilaian dari hali materi adalah sangat valid.

Pemaparan data validasi dari ahli media disajikan dalam tabel berikut:

Presentase data yang diperoleh dari skor validasi ahli media diperoleh sebanyak

$$
\begin{aligned}
V a h & =\frac{T s e}{T s h} \times 100 \% \\
& =\frac{62}{75} \times 100 \%=\mathbf{8 2} \%
\end{aligned}
$$

Mengacu pada tabel kriteria validasi maka hasil penilaian dari ahli media menggunakan persentase $82 \%$ adalah Sangat valid. Validasi ahli materi dan ahli media dilakukan untuk menguji media pembelajaran pop up book audiovisual tentang tata cara berwudhu pada anak TK B yang dikembangakan menggunakan teori, untuk medapatkan perolehan yang lebih baik dari hasil ahli materi dan ahli media maka pengembang melakukan analisis gabungan menggunakan rumus sebagai berikut:

$$
\begin{gathered}
V a h=\frac{V m a t+V m e d}{2}=\cdots \% \\
\frac{84 \%+82 \%}{2}=83 \%
\end{gathered}
$$

Melihat hasil di acu pada tabel kriteria validasi, maka hasil analisi gabungan dari ahli materi dan ahli media dengan presentase $83 \%$ adalah sangat valid.

1. Analisis Data Hasil Evaluasi Produk

dari Pengguna. Berikut pemaparan

hasil evaluasi dari ahli media:

$$
\begin{aligned}
V-p g & =\frac{\mathrm{T} s e}{\mathrm{~T} s h} \times 100 \% \\
& =\frac{46}{50} \times 100 \%=92 \%
\end{aligned}
$$

2. Analisis Data Hasil Penilaian Capaian Belajar Anak. Berikut pemaparan Hasil Evaluasi Produk dari Hasil Penilaia Capaian Belajar Anak.

$$
\begin{aligned}
V-a u & =\frac{\text { Tse }}{\text { Tsh }} \times 100 \% \\
& =\frac{263}{270} \times 100 \%= \\
& =97 \%
\end{aligned}
$$

Berdasarkan tabel diatas terdapat 9 item validasi. Jumh skor yang didapat dari penilaian capaian belajar 6 anak adalah 263 . Mengacu pada kriteria validasi, maka hasil capaian belajar anak dengan presentase $97 \%$ adalah sangat efektif. Untuk menyimpulkan hasil dari validasi ahli, pengguna, dan validas audience dapat dihitung menggunkan rumus:

$$
\mathrm{V}=\frac{\mathrm{V}-a h+\mathrm{V}-p g+\mathrm{V}-a u}{3}=\cdots \%
$$

$$
=\frac{87 \%+92 \%+97 \%}{3}=92 \%
$$

\section{KESIMPULAN}

Kesimpulan dari penelitian ini adalah bertujuan untuk mengembangkan produk pop up book audiovisual yang efesien, menarik, dan juga efektif dalam mengajarkan cara berwudhu pada anak usia dini. Berdasarkan uji kelayakan media terkait aspek keefesiensian, kemenarikan, presentase hasil uji keefesiensian media penilaian oleh ahli materi dan ahli media. Hasil presentase didapatkan berdasarkan hasil gabungan antara validasi ahli materi dan validasi ahli media adalah $88 \%$. Mengacu pada tabel kriteria validasi, maka hasil penilaian validasi dengan presentase $88 \%$ adalah sangat efesien.

Kemenarikan media pembelajaran pop up book audiovisual tentang tata cara berwudhu dinilai oleh pengguna yaitu guru/orangtua saat melakukan uji coba. Hasil persentase yang didapatkan berdasarkan penilaian oleh pengguna adalah $92 \%$. Mengacu pada tabel kriteria 
validasi, maka hasil penilaian validasi dengan presentase $92 \%$ adalah sangat praktis dan menarik. Uji coba juga menghasilkan data hasil penilaian capaian belajar anak untuk melihat keefektifan dari media pembelajaran pop up book audiovisual tata cara berwudhu. Hasil persentase penilaian capaian belajar anak adalah $97 \%$. Mengacu pada tabel kriteria validasi, maka hasil penilaian validasi dengan presentase $97 \%$ adalah sangat efektif.

Hasil validasi gabungan dari ahli materi, ahli media, pengguna dan juga audience adalah 92\%. Menacu pada tabel vaidasi, maka hasil validasi media pembelajaran pop up book audiovisual tentang tata cara berwudhu pada anak TK Kelompok B dengan persentase 92\% adalah Sangat Layak.

\section{DAFTAR PUSTAKA}

Azzam, A.A. M.\& Sayyid, A.W. S. H. 2018. Fiqih Ibadah. Jakarta: Amzah.

Akbar, S. 2013. Instrumen Perangkat Pembelajaran. Bandung: PT Remaja Rosdakarya

Asyhar, R. 2011. Kreatif Mengembangkan Media

Pembelajaran. Jakarta: Gaung Persada (GP) Press Jakarta.

Sugiyono. (2016). Metode Penelitian Kuantitatif, Kualitatif dan $R \& D$. Bandung: PT. Alfabet.

Suyadi \& Ulfah (2015). Konsep Dasar Paud, Cetakan Ke-4. Bandung : PT. Remaja Rosdakarya. 